\title{
Papéis de gênero e divisão das tarefas domésticas segundo gênero e cor no Brasil: outros olhares sobre as desigualdades
}

\author{
Felícia Picanço* \\ Clara Maria de Oliveira Araújo ${ }^{\star \star}$ \\ Maira Covre-Sussai ${ }^{\star \star \star}$
}

\begin{abstract}
A adesão ao modelo tradicional de família nunca foi uniforme. Estudos sobre famílias negras nos EUA e no Caribe, por exemplo, mostram que as mulheres negras são menos propensas do que as brancas a oficializarem o casamento, são menos dependentes dos seus cônjuges e, do ponto de vista das atitudes, homens e mulheres afro-americanos tendem a ser mais tolerantes com mães que trabalham e mais igualitários em relação aos papéis de gênero. As diferenças são atribuídas aos constrangimentos socioeconômicos experimentados historicamente e às saídas construídas para lidar com eles. E no Brasil? 0 artigo aplica modelos de regressão linear múltipla para analisar os dados do survey Gênero, Família e Trabalho a partir das percepções em relação aos papéis de gênero, às práticas de divisão do trabalho doméstico entre os membros do casal e ao conflito na articulação trabalho reprodutivo (casa) e trabalho remunerado (trabalho) segundo gênero e raça. Os resultados apontam que, em relação às percepções sobre os papéis de gênero, as mulheres brancas são as mais igualitárias. Essa adesão cresce com a escolaridade e diminui com maior número de filhos e presença de cônjuge. Já os homens negros são os menos igualitários e essa assimetria é reduzida pela idade e maior número de filhos. Na divisão do trabalho, os homens negros são os mais igualitários e a adesão à igualdade aumenta com a escolaridade e com percepções mais igualitárias de papéis de gênero, enquanto as mulheres negras reportam relações menos simétricas, mas a simetria cresce com a escolaridade. Quanto ao conflito casa-trabalho, as mulheres negras declaram mais cansaço do que as brancas, mas este se reduz com a escolaridade e a presença de cônjuge.
\end{abstract}

Palavras-chaves: Gênero. Família. Papéis de gênero. Articulação casa-trabalho.

\footnotetext{
* Universidade Federal do Rio de Janeiro (UFR), Rio de Janeiro-RJ, Brasil (felicia@uol.com.br; https://orcid.org/00000001-5661-5782).

** Universidade Estadual do Rio de Janeiro (UERJ), Rio de Janeiro-RJ, Brasil (claramaria.araujo@gmail.com; https://orcid. org/0000-0002-6773-8582).

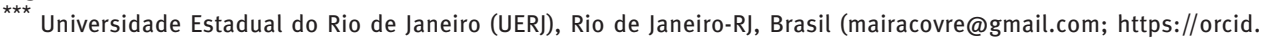
org/0000-0002-2052-4907).
} 


\section{Introdução}

O modelo tradicional de família - nuclear, heterossexual e formalizado institucionalmente - vem perdendo espaço nas sociedades contemporâneas, inclusive no Brasil. Isso não significa sua extinção enquanto prática ou valores culturais transmitidos entre e intragerações na orientação de escolhas e desejos sobre relações afetivas e conjugais. Ao contrário, tal modelo ainda responde por uma parcela importante das famílias e se assenta, sobretudo, em valores a partir dos quais se definem papéis de gênero desiguais e práticas cotidianas em relação a quem realiza as tarefas de reprodução da família (CROMPTON, 2006; THERBON, 2006; BADINTER, 2011; ITABORAí, 2017).

Ao longo das últimas décadas, as ciências sociais têm empreendido um esforço em mensurar valores e práticas. Em relação aos valores, Joas (2000) questiona se ainda trata-se de um conceito-chave das ciências sociais, ou, diante das dificuldades em operacionalizá-los na pesquisa empírica, podem ser substituídos por "atitudes", “práticas” ou “cultura”. As respostas a essa questão abriram espaço para um conjunto de novas pesquisas, cujos interesses são teóricos e metodológicos, isto é, como definir um conceito de valores e torná-lo mensurável nas pesquisas empíricas.

Os valores são ideais abstratos que funcionam como princípios orientadores dos comportamentos e avaliações que os indivíduos fazem sobre as ações, pessoas e situações; referem-se a objetivos desejáveis que motivam as ações, mas as transcendem assim como as situações momentâneas, e são hierarquizados de modo que a importância de um valor não é a mesma de outro (MILES, 2015; SCHWARTZ, 2012). Segundo Miles (2015), os valores fundamentam a cultura, têm implicações importantes para as ações, estão ligados ao self(JOAS, 2000) e operam via o processo dual da cognição, isto é, por meio de processos pré-reflexivos e automáticos e de processos conscientes e reflexivos. Segundo Lomazzi e Seddig (2020), os valores não são mensuráveis diretamente, mas sim a partir de crenças, atitudes e opiniões; logo, medir tais aspectos é a forma de se chegar mais perto dos valores. Nesse sentido, não se trata de colocar opiniões e atitudes no lugar dos valores, mas sim encontrar possibilidades de mensurá-los.

As práticas, por sua vez, são aqui entendidas como os comportamentos que se desenrolam no curso das situações, orientadas não apenas pelas dimensões chamadas de objetivas (necessidades de reprodução básica da vida e condições socioeconômicas), mas também por valores, respondendo aos papéis sociais. Já os papéis são expectativas de comportamento definidos de acordo com valores e normas sociais e associados às posições na estrutura de estratificação das sociedades (LINDSEY, 2016). E, enquanto a desigualdade descreve a distribuição desigual de algum bem (renda, educação, saúde, etc.), a estratificação é gerada quando o fato de possuir determinada quantidade e/ou tipo de bem ou característica hierarquiza os indivíduos ou grupos em uma estrutura de posições. Nesse sentido, os papéis sociais também respondem pela manutenção das estruturas de desigualdade e estratificação das sociedades. Buscar mensurar 
percepções, valores e práticas tem sido crucial para entendermos as resultantes dessas imbricações sociais.

A mensuração de valores e práticas de gênero teve início nas pesquisas de opinião pública realizadas nos anos 1950 pelo Instituto Gallup no Estados Unidos (FERREE, 1974). Nos anos 1970, o General Social Survey, criado para acompanhar as mudanças nas atitudes e comportamentos da sociedade americana, se preocupou em mensurar opiniões sobre lugares de homens e mulheres na sociedade. Na Europa, algumas instituições e inciativas produzidas por diferentes agentes e com distintas formas de organização também tiveram curso desde a década de 1970, tais como o Eurobarometer, European Values Study, o World Values Suvey e o International Social Survey Programme. Outras iniciativas foram sendo implementadas em diversas partes do mundo, como Latinobarômetro, Afrobarometer, Asianbarometer, etc.

As pesquisas de survey sobre papéis de gênero, ao longo das décadas, foram se constituindo como um campo central para o estudo sobre as sociedades contemporâneas, incorporando dimensões não exploradas nas primeiras ondas de pesquisa de opinião, em especial a questão da divisão das tarefas domésticas entre membros da família, com maior atenção para a divisão das tarefas entre casais e tempo gasto com a realização das tarefas de reprodução social da família (atividades domésticas e cuidados). Umas das iniciativas de maior destaque internacional é o survey Family and Changing Gender Roles do Internacional Social Survey Programme (ISSP), que teve sua primeira rodada em 1988 e a última aplicada em 2012.

O Brasil participou da pesquisa de 2002 do ISSP (ARAÚJO; SCALON, 2005), mas não conseguiu participar da rodada de 2012. Em 2016 foi realizado o survey "Gênero, Família e Trabalho", baseado na rodada de 2012 do ISSP (ARAÚJO et al., 2018). 0 objetivo deste artigo é analisar as percepções em relação a papéis de gênero, práticas de divisão do trabalho doméstico e percepção de cansaço na articulação entre trabalho reprodutivo (casa) e atividade remunerada (trabalho), aqui nomeado conflito casa-trabalho. São utilizados os dados do survey "Gênero, Família e Trabalho", mas introduzindo a comparação entre grupos sociais por gênero e raça, como forma de analisar de que maneira as estratificações de gênero e raça na sociedade brasileira estão relacionadas à adesão a papéis de gênero e práticas de divisão do trabalho reprodutivo mais igualitárias, bem como verificar se e como a sobrecarga de trabalho reprodutivo nas mulheres impacta na percepção de cansaço na articulação entre trabalho reprodutivo (casa) e atividade remunerada (trabalho). Desse modo, também com base nos dados do survey, ampliaremos as análises de Heringer e Miranda (2005) e Alves e Carvalho (2018), que trataram por raça/cor, mas elegeram apenas as percepções, e os estudos de Araújo, Picanço, Cano e Veiga, (2018) e Gama, Sorj, Romero e Veiga (2018), que, embora tenham abordado as percepções e práticas, não consideraram os grupos de gênero e raça.

0 artigo é composto por quatro seções, além desta introdução e da conclusão. Na próxima, é apresentado o problema de pesquisa que deu origem ao artigo e, para tanto, é traçado 
um panorama geral da população brasileira acima de 18 anos em relação a conjugalidade, escolaridade, inserção ocupacional, desigualdade de renda, participação na renda familiar e horas dedicadas ao trabalho doméstico. Este panorama, usando dados da PNAD (2014), nos ajuda a situar melhor a relação entre classe, raça e gênero, uma vez que o survey não apresenta de modo detalhado dados sobre renda e tipos de ocupação. Posteriormente, são abordados os aspectos metodológicos do artigo, destacando os elementos do debate sobre a intersecção entre os marcadores sociais das desigualdades. Também descreve-se a população brasileira segundo gênero e raça segundo as percepções, práticas e conflito casa-trabalho. Por fim, são analisados os resultados das regressões para os índices de papéis de gênero, práticas e conflito família-trabalho.

\section{Configurações familiares e papéis de gênero}

Nos Estados Unidos, embora exista uma grande variação de perspectivas teóricas e desenhos de pesquisa, a literatura aponta que, do ponto de vista demográfico, as mulheres afro-americanas são igualmente propensas a viver em uma união consensual, mas são menos propensas do que as mulheres brancas a oficializar essa união em forma de casamento (LICHTER et al., 1992; RALEY, 1996; SMOCK, 2000), além de serem menos dependentes dos seus cônjuges (LICHTER et al., 1992; RALEY, 1996). Do ponto de vista das atitudes de gênero, homens e mulheres afro-americanos tendem a ser mais tolerantes com mães que trabalham e mais igualitários em relação aos papéis de gênero (BURGESS, 1994; BUCHANAN; SELMON, 2008). Ter um cônjuge, ${ }^{1}$ em geral, impacta negativamente na adesão a papéis igualitários de gênero com mais intensidade entre os brancos (BLEE; TICKAMYER 1995). Ter filhos influencia mais na adesão a percepções mais igualitárias entre as mulheres negras do que entre as brancas, em parte porque o culto à domesticidade não é central para as negras (BURGESS, 1994; COLLINS, 1999). No entanto, Vespa (2009) conclui que ter um cônjuge impacta as atitudes de homens e mulheres de diferentes formas: maior adesão à percepção igualitária de gênero entre os negros, em especial entre mulheres negras, e menor adesão entre os brancos. Ter filhos provoca maior adesão a percepções igualitárias de gênero apenas entre as mulheres negras. Ter um trabalho em tempo integral está associado à menor adesão a percepções igualitárias entre homens, em especial para os negros.

Segundo estudos históricos e censitários, no Brasil, desde os tempos coloniais, mulheres negras também participam um pouco mais da força de trabalho e são menos propensas ao casamento oficial (IPEA, 2017; COVRE-SUSSAI, 2016; ESTEVE et al., 2016; SAMARA; COSTA, 1997). Mas há alguns aspectos da estrutura de estratificação e desigualdades de gênero e raça no Brasil que merecem destaque e não estão disponíveis no survey; por isso os dados da Pesquisa Nacional por Amostra de Domicílio (PNAD) de 2014 serão utilizados

\footnotetext{
${ }^{1}$ Neste estudo, o termo cônjuge é usado indiscriminadamente para cônjuges (oficialmente casados/as) ou parceiros/as (vivendo em uniões consensuais).
} 
para apresentar um retrato da população brasileira acima de 18 anos segundo gênero e raça/cor. Aqui, os dados da PNAD complementam e detalham as informações não coletadas no survey "Gênero, Família e Trabalho". Isso é importante a fim de que tenhamos claro o panorama de fundo em relação ao qual analisamos valores e atitudes, em períodos próximos.

A estrutura familiar do brasileiro se caracteriza da seguinte forma: no que se refere à condição na família, 37,7\% das mulheres negras e 33,4\% das brancas acima de 18 anos são pessoas de referência; em relação à conjugalidade, $57,1 \%$ das mulheres negras e $57,6 \%$ das brancas declararam estar vivendo conjugalmente com alguém, das quais $42,2 \%$ das negras e $28,5 \%$ das brancas vivem em união estável. Observa-se que no Brasil, tal como nos EUA, a maior diferença entre as mulheres negras e brancas está na oficialização da união.

Em relação ao tipo de família, $23 \%$ das mulheres negras e $18 \%$ das brancas estão em famílias compostas apenas por mães e filhos (maiores e/ou menores de 14 anos). As demais variações sinalizam que as mulheres brancas inserem-se mais em famílias formadas por casais sem filhos e as negras em famílias do tipo casal com filhos maiores de 14 anos. A média de filhos é de 3, para as mulheres negras, e 2,6, para as brancas, mas a diferença é que $61,1 \%$ das brancas e $53 \%$ das negras têm até dois filhos.

A imagem recorrente é de que as mulheres mais pobres são as que tendem a ser pessoas de referência. Porém, observou-se que, por diferentes processos socioeconômicos, o percentual de mulheres consideradas pessoas de referência da família varia pouco entre os quintis de renda. Mesmo com a pequena variação, as mulheres do 10 quintil de renda têm o maior percentual de pessoas de referência na família (38\%) e as do $4^{\circ}$ quintil, o menor $(32,4 \%)$.

As mulheres negras são aquelas que estão proporcionalmente em maior número no $1^{\underline{0}}$ quintil (20\%) e as brancas, aquelas com menor presença $(7,9 \%)$ - ver Tabela 1 do Anexo. Entre as mulheres negras do $1^{\circ}$ quintil, $38,9 \%$ eram pessoas de referência na família, $61,3 \%$ viviam conjugalmente e, destas, 38,5\% eram casadas no civil. Entre as mulheres brancas

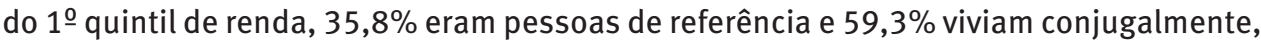
das quais $50,1 \%$ eram casadas oficialmente. Dessa forma, não temos evidências de que no Brasil há uma diferença significativa entre mulheres brancas e negras em relação à condição na família e conjugalidade, nem mesmo quando analisamos por renda. A diferença encontrada está na oficialização da união.

Outro aspecto que somente a PNAD pode fornecer mais informação refere-se à inserção ocupacional das mulheres. A participação no mercado de trabalho em 2014, momento anterior à crise econômica que se iniciou em 2015, indica patamares de atividade bastante similares entre as mulheres acima de 18 anos: 53,9\% das negras e 54,9\% das brancas estão empregadas ou à procura de emprego, estando nesta última condição $7,5 \%$ das negras e $5 \%$ das brancas.

A inserção ocupacional, aqui medida por meio de categorias sócio-ocupacionais (ver Tabela 2 do Anexo), evidencia as desigualdades raciais e de gênero historicamente reproduzidas. No topo da hierarquia estão quatro categorias: profissionais liberais, dirigentes, 
proprietários empregadores e profissionais de nível superior. Somente nesta última as mulheres aparecem em vantagem. 0 acesso a melhores posições na estrutura sócio-ocupacional se dá para as mulheres negras por meio da categoria de profissionais de nível superior. Mesmo assim sua representatividade está 5 pontos percentuais abaixo das mulheres brancas. Na base da estrutura, as mulheres negras estão mais concentradas do que as brancas em duas categorias: as ocupações no serviço doméstico (brancas somam 10,1\% e negras $17,6 \%$ e nas ocupações rurais ( $7,8 \%$ e $12,8 \%$, respectivamente). Vale ressaltar que essas categorias ocupacionais são pouco protegidas em relação a acesso a direitos.

A participação na renda familiar também constitui aspecto relevante para a caracterização das mulheres. No Brasil, 49,3\% das mulheres negras e 49,3\% das brancas contribuem com até $30 \%$ da renda domiciliar, enquanto para os homens esse percentual é de $24,1 \%$ para brancos e $26,6 \%$ para negros. Podemos olhar este dado a partir de duas perspectivas: uma é colocar a ênfase no fato de que metade das mulheres contribui "apenas" com até $30 \%$ da renda familiar; a outra é ressaltar que $50 \%$ das mulheres são responsáveis por mais de $30 \%$ da renda familiar e, entre estas, cerca de $20 \%$ participam com mais de $60 \%$ da renda familiar.

0 crescente envolvimento das mulheres no mercado de trabalho e na participação da renda não as retira da intensa responsabilização sobre a realização das tarefas domésticas. Ainda segundo a PNAD de 2014, cerca da metade dos homens brancos e negros declararam não se envolver em tarefas domésticas ( $47,8 \%$ dos brancos e $49,4 \%$ dos negros). Entre as mulheres, $91,6 \%$ das negras e $88,3 \%$ das brancas afirmaram realizar afazeres domésticos. Este dado dá conta de uma parte da questão, pois o maior desafio está no tempo delegado à realização das tarefas domésticas: em média os homens brancos e negros dedicam 11 horas semanais, enquanto as mulheres brancas despendem 25 horas nessas atividades e as negras 26 horas.

As mulheres brancas e negras, quando pessoa de referência na família, gastam em média 25 e 26 horas semanais nos afazeres domésticos, respectivamente, as casadas oficialmente despendem 28 e 29 horas em média e as que vivem conjugalmente, 28 e 29 horas em média. No que se refere aos quintis de renda, no $1^{0}$ quintil, brancas e negras dedicam ao trabalho doméstico não remunerado 30 horas semanais em média e, no 5은 quintil, 22 horas. Não ter um trabalho aproxima a média de horas das mulheres brancas (30) e negras (30), mas entre as que trabalham há diferença, pois as brancas dedicam em média 20 horas e as negras 22 horas semanais aos afazeres domésticos.

Os dados da PNAD sobre as mulheres que trabalham, sua jornada de trabalho, categoria sócio-ocupacional e participação na renda familiar revelam como as desigualdades ocupacionais estão diretamente vinculadas às horas dedicadas aos afazeres domésticos. Numa jornada de trabalho remunerado de 25 horas semanais, as mulheres negras dedicam em média 26 horas aos afazeres domésticos e as brancas 24 horas. Nas jornadas de 36 a 44 horas de trabalho, as negras gastam em média 19 horas e as brancas, 18 horas. Nas jornadas acima de 44 horas, as negras despendem 20 horas e as brancas, 19. Em relação 
às categorias sócio-ocupacionais, as mulheres brancas e negras que são profissionais liberais trabalham, em média, 13 horas semanais e nas ocupações de serviços pessoais e ocupações no serviço doméstico a média sobe para 22 horas. Ainda, as mulheres brancas e negras, cujas rendas do trabalho compõem até $30 \%$ da renda familiar, são aquelas que dedicam, em média, 28 horas por semana ao trabalho doméstico não remunerado. Entre as mulheres que contribuem com mais de $30 \%$ para renda familiar, a média cai para 22 horas para as brancas e 24 para as negras.

As dimensões aqui abordadas a partir dos dados da PNAD assinalam que as desigualdades entre mulheres brancas e negras estão localizadas mais claramente nas condições socioeconômicas, pois as negras são proporcionalmente mais pobres e estão mais inseridas em ocupações de menor renda e prestígio - um dado já largamente conhecido. No entanto, observamos que mulheres negras e brancas se aproximam em relação à condição na família e conjugalidade e, estando em condições iguais de conjugalidade, renda e inserção ocupacional, tendem a dedicar ao trabalho não remunerado um número médio de horas muito parecido.

Este panorama permite identificar que a divisão sexual do trabalho doméstico é desigual e desfavorável às mulheres, uma vez que as responsabilidades com as tarefas de reprodução das famílias recaem majoritariamente sobre elas, independentemente da cor/ raça. A concentração do trabalho doméstico nas mulheres é atenuada pelas condições socioeconômicas, aqui medidas pela renda e inserção ocupacional. Considerando que o número de horas dedicadas pelos homens não varia, é de se supor que isso se dá, muito provavelmente, devido à delegação do trabalho doméstico para outras mulheres o realizarem, em geral negras e pobres.

Saindo dos dados da PNAD, constatamos que em relação aos valores as pesquisas ainda são poucas. Os estudos de Heringer e Miranda (2005) e Alves e Carvalho (2018) inauguraram uma linha de investigação sobre valores igualitários em relação aos papéis de gênero por raça/cor a partir dos dados dos surveys realizados no Brasil. No que se refere às atitudes de gênero, Heringer e Miranda (2005) analisaram os dados do survey “Família e Papéis de Gênero no Brasil”, realizado em 2003, e elegeram a concordância com a afirmação "os homens devem ganhar dinheiro e as mulheres cuidar das tarefas domésticas" para investigar se gênero e raça importam na adesão aos papéis mais tradicionais de gênero que a concordância com esta afirmação representa. As autoras concluíram que os homens negros são aqueles que mais concordam com a afirmação. Em seguida, utilizando testes estatísticos, mostraram que para os brancos a associação entre percepção e gênero só existe nas rendas mais baixas e para os negros em mais de uma faixa de renda. Por escolaridade, só há associação entre a concordância com a afirmação e cor/raça quando a escolaridade é a mais baixa (ensino fundamental). Por fim, Heringer e Miranda (2005) inseriram o sexo para analisar a diferença da concordância entre as mulheres brancas e negras controlando renda, escolaridade e presença de filhos. Em relação à renda, somente entre as mulheres negras existe diferença. Quanto à escolaridade e ter filhos, existe associação tanto entre 
as brancas quanto entre as negras. Ou seja, para as mulheres, escolaridade e ter filhos são dimensões fundamentais para compreender a adesão a valores mais ou menos tradicionais, lembrando que neste estudo a adesão foi medida apenas pela concordância à afirmação apresentada anteriormente.

Alves e Carvalho (2018), utilizando os dados da pesquisa "Gênero, Família e Trabalho", realizada em 2016, analisam a variação por raça/cor da concordância com algumas das afirmações que expressam papéis de gênero e concluem, usando modelo logístico, que a raça/cor é estatisticamente significante em quatro das cinco afirmações, mencionadas a seguir. Na frase "Uma mãe que trabalha fora de casa pode ser tão boa mãe quanto uma mãe que não trabalha", as diferenças por cor/raça não foram estatisticamente significativas. Nas demais as diferenças foram significativas. Na frase "Em geral, a vida familiar fica prejudicada quando uma mulher trabalha em tempo integral”, são os brancos que mais concordam. Na frase "O trabalho do homem é ganhar dinheiro, o trabalho da mulher é cuidar da casa e da família", são os pardos que mais concordam. Na frase "Os homens deveriam dividir igualmente com as mulheres todas as tarefas domésticas", os amarelos/ indígenas são os que mais concordam. E na frase "Um pai ou uma mãe sozinho(a) pode criar o(a) filho(a) tão bem quanto um casal”, são os brancos que mais concordam com esta afirmação. Visto assim, não há uma prevalência entre os grupos de cor/raça para adesão a valores mais ou menos tradicionais, uma vez que variam na concordância.

Em seguida, os autores analisam a raça/cor somada a outras variáveis como sexo, escolaridade e região geográfica, mas o impacto das diferentes variáveis fica mais visível quando os autores optam por fazer regressões logísticas inserindo diversas variáveis, além da cor/raça, para explicar a concordância com as frases. As únicas variáveis que foram constantes nas cinco frases foram a região geográfica e a religião dos indivíduos. Sexo e idade também parecem ser bastante relevantes, uma vez que estiveram presentes em quatro das cinco frases. Raça/cor tem efeito significativo em três das cinco frases: "Em geral, a vida familiar fica prejudicada quando uma mulher trabalha em tempo integral"; "O trabalho do homem é ganhar dinheiro, o trabalho da mulher é cuidar da casa e da família"; e "Um pai ou uma mãe sozinho(a) pode criar o(a) filho(a) tão bem quanto um casal". Segundo os autores, os resultados expressam a importância do contexto e da geração em que as pessoas estão inseridas para a determinação dos valores igualitários.

Conquanto os estudos de Heringer e Miranda (2005) e Alves e Carvalho (2018) tragam novas contribuições, algumas perguntas permanecem em aberto: mulheres negras e brancas e homens negros e brancos dividem as tarefas da mesma forma com seus cônjuges? Quais grupos de gênero e cor sentem maior carga na articulação casa-trabalho? Os efeitos da idade, escolaridade e trabalho têm a mesma intensidade para os grupos de gênero e raça/cor na adesão a valores menos tradicionais de gênero, em práticas mais igualitárias e em declaração de menor conflito casa-trabalho? São perguntas sobre as quais pretendemos avançar neste artigo. 


\section{Estratégias metodológicas}

A pesquisa amostral "Gênero, Família e Trabalho" foi construída com base no questionário aplicado na quarta rodada do survey "Family and Changing Roles" do ISSP. ${ }^{2}$ Elegemos as perguntas que expressavam as três dimensões de análise: papéis de gênero; práticas da divisão do trabalho doméstico; e conflito na articulação trabalho reprodutivo (casa) e atividade remunerada (trabalho), doravante nomeado conflito casa-trabalho. A partir das questões, construímos para cada dimensão um índice que sintetiza as respostas dadas às questões selecionadas. Os índices variam de $0 \mathrm{a} 1$, em que 1 é o polo positivo, isto é, papéis de gênero e práticas mais igualitários e ausência de conflito casa-trabalho (para mais detalhes sobre a construção dos índices ver Quadros 1, 2 e 3 do Anexo).

Inicialmente descrevemos as questões utilizadas para a composição dos índices e, em seguida, analisaremos as variações dos índices e calcularemos regressões para verificar: como a geração, medida pela idade, capitais e repertórios culturais, medidos pela escolaridade, e ter cônjuge e número de filhos são variáveis que expressam a carga de trabalho reprodutivo na casa; as horas dedicadas ao trabalho remunerado como forma de medir a conjugação casa-trabalho; o modelo de mulher com o qual o respondente conviveu na infância e adolescência, medido por ter tido uma mãe que trabalhou; e a adesão a sistema de valores religiosos, medida pela frequência a culto religioso.

Gênero e raça/cor foram utilizados para definir grupos sociais para os quais direcionaremos nossa análise. Desse modo, gênero e raça/cor não são variáveis independentes, mas sim grupos sociais que exprimem relações sociais estruturalmente desiguais que conformam suas oportunidades e experiências.

As imbricações entre gênero, raça e classe, dentre outras, assentaram nas últimas décadas sobre as perspectivas interseccional (CRENSHAW, 1994; CHO et al., 2013; COLLINS, 2015) e da consubstancialidade (KERGOAT, 2010). Enquanto a primeira ganhou enorme visibilidade por meio da luta política, em especial do feminismo negro americano e intelectuais negras, a segunda circula de forma restrita no campo da sociologia materialista feminista, em especial a francesa. Hirata (2014) e Garneau (2018) procuram distinguir as duas perspectivas não para torná-las competitivas ou excludentes, mas sim para apontar as distinções epistemológicas entre elas. A perspectiva consubstancial parte da tríade sexo, classe e raça para definir relações sociais estruturais; na perspectiva interseccional, a interseção é de geometria variável, isto é, inclui em geral o par gênero-raça, mas pode considerar outras categorias e relações sociais, tais como classe, sexualidade, religião, condição de deficiência, entre outras.

Ainda que o gênero e raça apareçam nas duas perspectivas como centrais, alguns autores vêm promovendo um debate com o objetivo de apontar os limites das perspectivas

\footnotetext{
2 Detalhes sobre a pesquisa e sua metodologia podem ser encontrados em Araújo et al. (2018). A pesquisa entrevistou 1.575 (com n. final igual a 1.560) pessoas maiores de 18 anos, em todas as regiões do Brasil, por meio de uma amostra domiciliar probabilística, com um erro amostral de $+/-2,5 \%$, considerando um nível de significância de 0,05 se fosse uma amostra aleatória simples.
} 
para tratar do homem negro (CURRY, 2017; O'CONNOR et al., 2019; OLUWAYOMI, 2020). Assim, a perspectiva interseccional não estaria atenta ao sofrimento, dor e morte dos homens e garotos negros, uma vez que reproduz, em grande medida, a imagem do homem negro a partir das categorias de hipermasculinidade, ou seja, a partir dos excessos da masculinidade hegemônica.

Não é propósito deste artigo aprofundar o debate, mas sim evidenciar que, por diferentes caminhos, tanto a interseccionalidade como a consubstancialidade buscam identificar os mecanismos por meio dos quais as desigualdades de gênero, raça e classe são engendradas e estão imbrincadas na vida social. Mas as consequências metodológicas dessas perspectivas podem ser variadas e, por isso, teceremos algumas breves considerações a respeito.

Garneau (2018) destaca que podemos identificar duas posições na construção dos objetos de pesquisa: a nominalista, na qual o objeto será conhecido por meio da construção feita pelos sujeitos; e o realismo, posição na qual o objeto existe independentemente da construção que os sujeitos fazem sobre suas experiências. A autora classifica o feminismo pós-estruturalista na posição nominalista, a perspectiva consubstancial na posição do realismo, uma vez que as relações de gênero, raça/cor e classe estão dadas, e a interseccionalidade entre uma posição e outra, pois concebe as categorias e identidades sem recusar a dimensão estrutural na qual as identidades e categorias estão assentadas. Já MacCall (2005), considerando apenas a perspectiva interseccional, apresenta outras formas de sistematizar as alternativas metodológicas. A primeira é a opção anticategórica, em que as categorias de gênero, raça/cor e demais não são dadas a priori, mas sim no caminho da investigação, tendo como exemplo os estudos das feministas pós-estruturalistas e identificada com a posição nominalista. A segunda é intracategórica, cuja opção é eleger uma categoria como central e analisar as demais categorias internamente, isto é, escolher por exemplo o gênero e analisar a dimensão racial. Segundo a autora, esses estudos tendem a eleger um grupo específico como objeto de pesquisa (mulher negra ou homem negro). A terceira é a opção intercategórica, que supõe reconhecer analiticamente a relação entre as categorias prévias escolhidas e as desigualdades e colocar estas relações no centro das análises. Isso implica comparar os grupos sociais construídos a partir da combinação entre categorias.

Com efeito, acompanhando esta aproximação epistemológica e metodológica feita por Garneau (2018), somada à tipologia de McCall (2005), há uma aposta na literatura em tratar a virada interseccional nos estudos quantitativos sobre desigualdade de gênero e raça não mais utilizando gênero (ser homem ou mulher) e raça/cor (brancos, negros e demais categorias raciais) como efeito sobre variáveis. Isto é, tratar da abordagem realista (GARNEAU, 2018) e intercategórica (McCALL, 2005). A escolha é, então, por eleger categorias centrais, produzir combinações e construir grupos sociais (mulher negra, mulher branca, homem negro, homem branco) para analisar se as variáveis do modelo explicam a variação da variável dependente da mesma forma em todos os grupos sociais (HANCOCK, 2013). 
Nesse sentido, a análise aqui desenvolvida se alinha com as perspectivas interseccionais e consubstanciais que concebem a articulação entre gênero, raça/cor e classe como constitutiva do sistema de estratificação social vigente no país. Os papéis e as práticas de gênero serão, portanto, analisados por meio da comparação entre grupos de gênero e cor: mulheres negras, mulheres brancas, homens negros e homens brancos.

\section{Papéis de gênero, práticas e conflito casa e trabalho: o survey}

Esta seção apresenta os dados do survey "Gênero, Família e Trabalho" (n. 1.560), realizado em 2016 a partir de uma amostra representativa da população brasileira acima de 18 anos. As mulheres negras (autodeclaradas pardas e pretas) somam 26,2\% e as brancas são $25,8 \%$. Os homens negros (autodeclarados pardos e pretos) correspondem a $26,8 \%$ e os brancos são $18,7 \%$. As mulheres brancas têm a maior média de idade $(46,4$ anos), seguidas pelos homens brancos $(44,6)$, homens negros $(44,5)$ e mulheres negras (44). Visto pela média de idade, as diferenças são pequenas, mas identificamos que as mulheres negras e os homens brancos apresentam os menores percentuais de pessoas acima de 60 anos (cerca de $17 \%)$, em relação às mulheres brancas (22\%) e aos homens negros (20\%) nesta faixa etária.

A configuração familiar será descrita em função da conjugalidade, número de filhos e número de moradores residentes no domicílio. Em relação à conjugalidade, as mulheres negras registram o menor percentual de presença de cônjuge $(48,4 \%)$ se comparadas às brancas (56,2\%); já os homens negros são aqueles que mais declararam estar vivendo conjugalmente com alguém (57\%), considerando-se todos os grupos. Em relação à presença de filhos, há pouca diferença no percentual das pessoas sem filhos. A discrepância está no número de filhos, sendo que as mulheres negras são as que mais declararam ter quatro filhos ou mais (28,5\%), seguidas pelos homens negros $(20,8 \%)$ e, em menor proporção, pelos homens brancos (3,4\%) e mulheres brancas $(9,5 \%)$.

Os arranjos familiares são, então, em sua maior parcela compostos por um casal com filhos, em especial para os homens negros (53,3\%), seguidos pelos homens brancos $(47,8 \%)$, mulheres brancas $(46,8 \%)$ e mulheres negras (44,6\%). As mulheres negras apresentam o maior percentual de pessoas que não vivem conjugalmente e têm filhos $(29,5 \%)$, seguidas pelas mulheres brancas $(24,4 \%)$. As famílias negras são mais numerosas: $31,5 \%$ das mulheres negras e $26,3 \%$ dos homens negros estão em domicílios com cinco ou mais pessoas, quase o dobro dos percentuais dos homens brancos (14\%) e das mulheres brancas (15,9\%).

As desigualdades socioeconômicas entre brancos e negros é uma das características estruturais na sociedade brasileira (HASENBALG, 1979; THEODORO, 2008; IPEA, 2017; GUIMARÃES, 2016; PASSOS; WAJNMAN, 2019) e têm na escolaridade e renda (além de outras dimensões) a síntese deste acúmulo histórico de desvantagens. A desigualdade educacional entre negros e brancos aqui pode ser apresentada destacando os níveis de 
escolaridade mais elevados, em que encontramos $40,1 \%$ dos homens brancos, $37,8 \%$ das mulheres brancas, $31,3 \%$ das mulheres negras e $30,8 \%$ dos homens negros com ensino médio completo; e $23,4 \%$ das mulheres brancas, $15,8 \%$ dos homens brancos, $8,4 \%$ dos homens negros e $8,1 \%$ das mulheres negras com ensino superior completo.

A desigualdade de renda se visibiliza tanto pela renda individual declarada quanto pela soma das rendas dos membros da família: $35 \%$ das mulheres negras têm renda individual de até um salário mínimo, seguidas por homens negros (23,3\%), mulheres brancas $(16,0 \%)$ e homens brancos (8,2\%); em famílias com renda total de até um salário mínimo, estão $20 \%$ das mulheres negras, $12,9 \%$ dos homens negros, $6,5 \%$ das mulheres brancas e $2,4 \%$ dos homens brancos.

A participação das mulheres no mercado de trabalho e, notadamente, a jornada de trabalho são elementos fundamentais para a compreensão do tempo delegado nas tarefas domésticas e nos cuidados. Os homens brancos registram a maior presença no trabalho remunerado $(74,7 \%)$, seguido pelos homens negros $(68,7 \%)$. Entre as mulheres, as brancas $(55,1 \%)$ tem 7 pontos percentuais de vantagem em relação às negras $(47,4 \%)$. Quanto à jornada de trabalho remunerado, $31,4 \%$ das mulheres negras e $27,4 \%$ das brancas trabalhavam até 35 horas semanais, 53,6\% das negras e 57,8\%, entre 36 e 44 horas, e 14,9\% das negras e $14,8 \%$ das brancas, acima de 44 horas por semana.

0 ingresso das mulheres no mercado de trabalho acima descrito é parte de um processo que já estava em curso, pois mais de $50 \%$ dos respondentes de todos os grupos afirmaram que suas mães trabalhavam quando eles tinham até 14 anos. Os homens negros apresentam o maior percentual $(54,4 \%)$, seguidos pelos homens brancos $(52,2 \%)$, mulheres negras $(51,3 \%)$ e mulheres brancas $(50,5 \%)$. A inserção das mulheres no mercado de trabalho é tida como uma conquista da modernidade ocidental, ao passo que a permanência da concentração do trabalho reprodutivo (tarefas domésticas e cuidados) sobre as mulheres é considerada um dado do tradicionalismo das relações e das desigualdades de gênero. No entanto, o ingresso no mercado de trabalho é também parte da necessidade de aquisição de renda para o sustento da família. É neste ponto que as mulheres negras e brancas se distinguem. Embora apresentem percentuais próximos de terem tido mães que trabalharam, as mulheres negras na faixa mais baixa de renda (até $\mathrm{R} \$ 788,00$, um salário mínimo quando a pesquisa foi aplicada) tinham quase o dobro de chances de terem tido uma mãe que trabalhava. Daí que as condições nas quais tal inserção é exercida vão ser distintas, mas não temos dados detalhados no survey para explorar tal questão.

Nas horas dedicadas às tarefas domésticas, a diferença entre mulheres negras e brancas é mais acentuada do que a observada para os dados da PNAD anteriormente descritos: as negras gastam em média de 27,8 horas por semana nos afazeres domésticos e as brancas dedicam em média de 24,2 horas a essas atividades. Para as mulheres que trabalham, embora menor, a diferença entre negras (26 horas em média) e brancas (23,9 horas em média) se mantém. Em grande medida, a diferença nas horas despendidas com atividades domésticas entre as mulheres que trabalham é produzida pela parcela daquelas que 
possuem jornada de até 35 horas semanais: entre essas mulheres, em média, as brancas gastam 28,9 horas com os afazeres domésticos e as negras, 33 horas.

Qual o sistema de valor que ancora as práticas? Para analisar os valores, recorremos às opiniões e atitudes de gênero e selecionamos as seguintes afirmações: "Mulher que trabalha fora pode ter relação tão carinhosa quanto a que não trabalha"; "Vida familiar fica prejudicada se a mulher trabalha fora"; "Trabalho do homem é ganhar dinheiro e da mulher cuidar da casa"; "Homens deveriam dividir igualmente as tarefas domésticas"; e "Pai ou mãe sozinho(a) pode criar o(a) filho(a) tão bem quanto um casal”. A Tabela 1 apresenta os percentuais de concordância a essas afirmações, por sexo e raça/cor.

TABELA 1

Percentual de respondentes que concordam com as afirmações, por sexo e cor/raça Brasil - 2016

\begin{tabular}{|c|c|c|c|c|c|}
\hline \multirow{3}{*}{ Afirmações } & \multicolumn{5}{|c|}{ Em porcentagen } \\
\hline & \multicolumn{2}{|c|}{ Homens } & \multicolumn{2}{|c|}{ Mulheres } & \multirow{2}{*}{ Total } \\
\hline & Brancos & Negros & Brancas & Negras & \\
\hline $\begin{array}{l}\text { Mulher que trabalha fora pode ter relação tão carinhosa } \\
\text { quanto a que não trabalha }\end{array}$ & 86,3 & 77,3 & 78,1 & 77,9 & 79,4 \\
\hline Vida familiar fica prejudicada se mulher trabalha fora & 58,6 & 51,6 & 55,0 & 51,6 & 53,3 \\
\hline $\begin{array}{l}\text { Trabalho do homem é ganhar dinheiro e da mulher cuidar } \\
\text { da casa }\end{array}$ & 30,1 & 42,0 & 24,1 & 31,1 & 31,9 \\
\hline Homens deveriam dividir igualmente as tarefas domésticas & 81,2 & 82,3 & 94,0 & 92,7 & 87,5 \\
\hline $\begin{array}{l}\text { Pai ou mãe sozinho(a) pode criar o(a) filho(a) tão bem quanto } \\
\text { um casal }\end{array}$ & 75,7 & 55,4 & 80,1 & 70,6 & 69,6 \\
\hline
\end{tabular}

Fonte: Pesquisa Gênero, Família e Trabalho, 2016.

De uma forma geral, ainda que exista adesão às percepções mais tradicionais de gênero, preponderam percepções igualitárias. Os homens brancos são os que mais concordam $(86,3 \%)$ com a afirmação de que a mulher que trabalha fora pode ter uma relação tão carinhosa com os(as) filhos(as) quanto as que não trabalham fora. Os demais grupos estão no mesmo patamar, sem muita diferença.

A alta adesão à afirmação anterior cai quando a questão passa a avaliar o prejuízo para a vida familiar, isto é, o amor incondicional de mãe e filho não é maculado com o trabalho fora, mas a instituição familiar sim. E são os homens brancos $(58,6 \%)$ que mais concordam com a afirmação "A vida familiar fica prejudicada se a mulher trabalha fora", seguidos pelas mulheres brancas (55\%) e os homens e mulheres negros, com $51,6 \%$ de concordância cada. Embora tenhamos diferentes sentidos para a ideia de prejuízo, ainda é uma percepção ativa quando se trata do trabalho das mulheres.

Umas das frases mais emblemáticas para mapear a adesão aos papéis tradicionais é "Trabalho do homem é ganhar dinheiro e da mulher cuidar da casa" e a concordância reflete a aproximação com esse modelo. Os homens negros são os que mais concordam (42\%) com a afirmação, seguidos pelas mulheres negras (31\%), os homens brancos (30\%) e as mulheres brancas (24\%). Notamos, então, que homens negros e mulheres brancas estão em polos apostos. Aqui, a imbricação entre gênero e classe parece se 
expressar com mais força, pois se, de um lado, a percepção dos homens tende a ser menos igualitária, de outro, sabemos que a escolaridade opera como um sinalizador de maior abertura aos papéis menos tradicionais. E vimos anteriormente que há significativa diferença de escolaridade de nível superior entre homens negros e brancos: respectivamente, $8,4 \%$ e $15,8 \%$

Mas esta alta adesão dos homens negros ao modelo mais tradicional parece contraditória se observamos a concordância com a afirmação de que homens deveriam dividir igualmente as tarefas domésticas. Verificamos que $81 \%$ dos homens brancos e $82 \%$ dos negros concordam que os homens deveriam dividir igualmente as tarefas domésticas. A concordância entre mulheres brancas e negras é de $94 \%$ e $92 \%$, respectivamente. Nota-se, então, que para os homens negros as duas esferas de percepção guardam relativa autonomia: aderir aos papéis tradicionais de gênero não implica desconhecer a necessidade de maior envolvimento de todos nas tarefas domésticas.

Embora não sejam as mulheres brancas que mais criam filhos sem a presença de cônjuge, são elas que mais concordam que pais ou mães sozinhas podem criar filhos(as) tão bem quanto casais, enquanto homens negros são os que menos concordam $(55,4 \%)$ com essa afirmação. As condições econômicas sob as quais as mulheres brancas criam sem cônjuge seus filhos pode ser um fator que pese neste achado, dado que entre as mulheres brancas que não têm cônjuge e têm filhos, $14,3 \%$ possuem renda individual acima de três salários mínimos e entre as mulheres negras este percentual é $0,8 \%$.

Se do ponto de vista dos valores há uma forte adesão à igualdade na distribuição das tarefas domésticas, já vimos anteriormente que a discrepância entre homens e mulheres em relação ao número médio de horas gastas é alto. 0 baixo envolvimento masculino nas tarefas domésticas é fartamente documentado nos estudos de gênero (DEDECCA, 2004; BRUSCHINI; RICOLDI, 2012; MALADOZZO et al., 2010; PINHEIRO, 2016). No survey, a realização das tarefas domésticas, por meio da qual analisaremos as práticas de divisão do trabalho doméstico, só foi perguntada para os respondentes que viviam conjugalmente com alguém. Foi indagado sobre quem "lava e passa”, "faz pequenos consertos", "cuida dos familiares doentes", "compra comida”, "limpa a casa”, "cozinha” e "lava a louça”. As respostas possíveis são: sempre eu, quase sempre eu, igualmente, quase sempre meu cônjuge ou sempre meu cônjuge. Apresentaremos a seguir os percentuais de respondentes que declararam a concentração das atividades no respondente, ou seja, as respostas sempre eu e quase sempre eu (Tabela 2 ), e os percentuais de respondentes que declararam que ambos realizam as tarefas (Tabela 3). 
TABELA 2

Proporção dos respondentes que vivem conjugalmente e responderam "sempre eu" ou "quase sempre eu" para a realização das tarefas

Brasil - 2016

\begin{tabular}{|c|c|c|c|c|c|}
\hline \multirow{3}{*}{ Tarefas } & & & \multicolumn{3}{|c|}{ Em porcentagen } \\
\hline & \multicolumn{2}{|c|}{ Homens } & \multicolumn{2}{|c|}{ Mulheres } & \multirow[t]{2}{*}{ Total } \\
\hline & Brancos & Negros & Brancas & Negras & \\
\hline Lava e passa & 8,4 & 8,4 & 82,2 & 82,6 & 47,1 \\
\hline Faz pequenos consertos & 74,5 & 70,5 & 11,9 & 18,6 & 43,3 \\
\hline Cuida dos familiares doentes idosos & 15,6 & 7,1 & 60,0 & 64,5 & 33,7 \\
\hline Compra comida & 19,5 & 13,3 & 29,2 & 43,6 & 26,9 \\
\hline Limpa a casa & 17,6 & 10,5 & 69,9 & 75,9 & 44,6 \\
\hline Cozinha & 14,3 & 11,7 & 80,2 & 82,1 & 48,4 \\
\hline Lava a louça & 27,9 & 13,4 & 57,1 & 67,2 & 41,7 \\
\hline
\end{tabular}

Fonte: Pesquisa Gênero, Família e Trabalho, 2016.

TABELA 3

Proporção dos respondentes que vivem conjugalmente e responderam que as tarefas são realizadas por ambos os membros do casal

Brasil - 2016

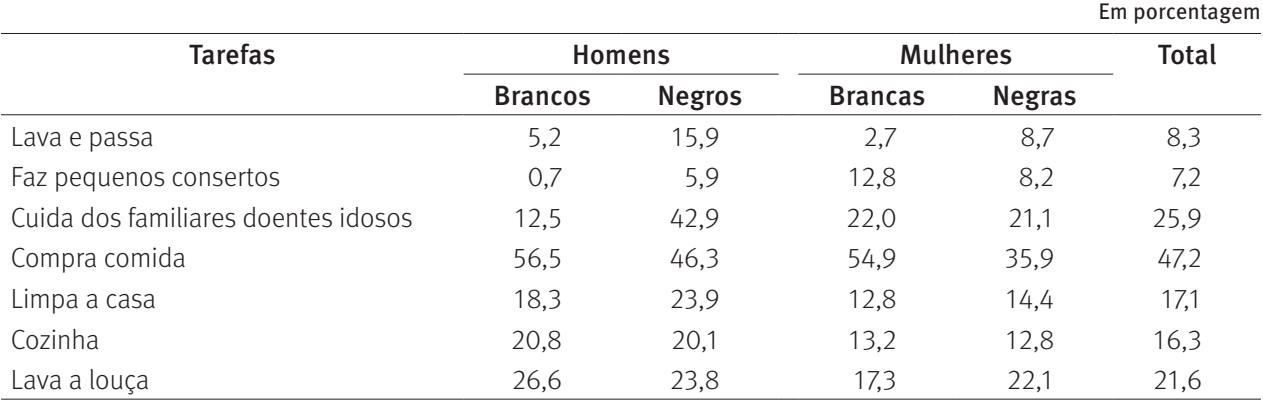

Fonte: Pesquisa Gênero, Família e Trabalho, 2016.

Apesar de muitos respondentes concordarem que ambos os membros do casal devem dividir igualmente as tarefas domésticas, homens e mulheres brasileiras dividem as tarefas domésticas baseadas em seu gênero. Mulheres negras realizam mais afazeres domésticos em geral do que as brancas, inclusive pequenos consertos, atividade predominantemente masculina. É muito provável que a presença de empregadas domésticas tenha impacto neste dado. A maior carga de trabalho das mulheres negras se expressa no dado que, entre os homens, são os negros que declararam menos participação na distribuição das tarefas. 0 menor diferencial está na compra de comida entre homens brancos e mulheres brancas e a maior concentração entre todos os grupos está nas mulheres negras.

Homens percebem a distribuição como mais igualitária do que as mulheres nas várias tarefas. Os negros reportaram mais compartilhamento das tarefas de comprar comida $(46,3 \%)$ e cuidado de familiares doentes $(42,9 \%)$, estando este último percentual de respostas bem distante daquele verificado nos outros grupos, sobretudo dos homens brancos, já que apenas $12,5 \%$ destes disseram cuidar igualmente de familiares doentes ou 
idosos. A tarefa percebida como menos concentrada em um dos membros do casal e com distribuição um pouco mais igualitária entre ambos é a de comprar comida (provavelmente ida ao supermercado). E os homens brancos são os que mais a percebem desse modo $(56,5 \%)$, seguidos pelas mulheres brancas $(54,6 \%)$, homens negros $(46,3 \%)$ e por fim mulheres negras, que reportam ser bem menor a divisão igualitária de compra de comida (35,9\%). A seguir, embora com percentuais de respostas não tão altos como os anteriores, encontra-se a atividade de lavar louça como a mais compartilhada pelo casal. Lavar e passar roupa recebeu as menores adesões à resposta "igualmente ou os dois juntos" por todos os grupos, com os homens negros percebendo-a um pouco mais como atividade compartilhada por ambos os cônjuges. Coerente com as respostas da Tabela 3, homens brancos e em seguida homens negros reportaram os menores percentuais de distribuição compartilhada e estes são na atividade de fazer pequenos consertos.

Os dados da pesquisa indicam que permanece uma distância considerável entre a “intenção", ou o que deve ser feito, e o "gesto", ou o que é feito e como é feito (ou dito que é feito). Todos os grupos concordam que os homens deveriam dividir igualmente as tarefas domésticas: as mulheres bem mais do que os homens - pouco mais de 10 pontos percentuais -, mas $81,2 \%$ dos homens brancos e $82,3 \%$ dos negros também concordam com esse enunciado. Já as Tabelas 2 e 3 revelam que o gesto ou a prática ainda não é esta, uma vez que, salvo raras exceções, a concentração das tarefas domésticas é nas mulheres.

0 compartilhamento das tarefas não significa necessariamente a adesão a valores igualitários. Aboim e Wall (2002) apontam que, em Portugal, o compartilhamento conjugal de determinadas tarefas e decisões, mais do que evidenciar equidade e autonomia, seria reflexo de um modelo "fusional" derivado mais da precariedade econômica do casal do que do compartilhamento intencional fruto de um valor mais igualitário de papéis de gênero.

O desequilíbrio na distribuição das tarefas domésticas torna a articulação família e trabalho remunerado um dos núcleos centrais no debate acadêmico e fora dele sobre as desigualdades de gênero, afetando as dinâmicas familiares ao elevar a carga de tensões e conflitos intrafamiliares e o estresse das mulheres (TORRES, 2004; BRUSCHINI, 2006; CROMPTON; LYONETTE, 2006; SINGLY, 2007; SARTOR, 2017). Para medir a resposta física e emocional dos inquiridos à articulação família e trabalho, a pesquisa perguntou àqueles que declararam ter um trabalho a frequência destas situações: "Chega do trabalho cansado demais", "É difícil cumprir as responsabilidades familiares por causa do trabalho" e "Tem chegado cansado no trabalho por causa das tarefas domésticas". As respostas possíveis são: algumas vezes na semana, algumas vezes no mês, uma ou duas vezes, ou nunca. Para a descrição dos percentuais e análises subsequentes, utilizamos a resposta "nunca" como referência. Afirmar "nunca” significa experimentar menos dificuldades em compatibilizar trabalho remunerado e obrigações familiares, seja por experimentarem condições menos adversas no trabalho, ou por se envolverem menos com atividades domésticas ou de trabalho remunerado. Os resultados são apresentados na Tabela 4. 
TABELA 4

Proporção de respondentes que possuem trabalho remunerado e responderam "nunca" para as afirmações

Brasil - 2016

\begin{tabular}{lccccccc}
\multicolumn{1}{c}{ Afirmações } & \multicolumn{2}{c}{ Homens } & & \multicolumn{2}{c}{ Mulheres } & Em porcentagem \\
\cline { 2 - 3 } & & Brancos & Negros & & Brancas & Negras & Total \\
\hline Chega do trabalho cansado demais & 45,6 & 41,9 & & 32,0 & 18,6 & 35,0 \\
$\begin{array}{l}\text { Difícil cumprir responsabilidades familiares por } \\
\text { causa do trabalho }\end{array}$ & 66,7 & 55,5 & & 62,7 & 36,1 & 56,7 \\
$\begin{array}{l}\text { Tem chegado cansado no trabalho por causa de } \\
\text { tarefas domésticas }\end{array}$ & 69,3 & 62,3 & & 59,8 & 41,7 & 58,6 \\
\hline
\end{tabular}

Fonte: Pesquisa Gênero, Família e Trabalho, 2016.

A disparidade de gênero é evidenciada em duas questões "Chega do trabalho cansado demais" e "Tem chegado cansado no trabalho por causa das tarefas domésticas”, em que os homens se distanciam das mulheres na declaração do "nunca”. Homens brancos são os que mais reportaram "nunca" terem experimentado tais dificuldades na articulação; a seguir estão os homens negros, que indicaram menos dificuldades, mas, em se tratando de cumprir responsabilidades familiares, ficam atrás das mulheres brancas. Entre as mulheres, as brancas mencionaram menos cansaço e dificuldades do que as negras em todas as três situações. As negras são de longe aquelas que se sentem mais penalizadas na articulação família e trabalho, relatando mais vezes chegarem cansadas do trabalho, difícil cumprir as responsabilidades familiares por causa do trabalho e chegarem no trabalho cansadas por causa das tarefas domésticas (Tabela 4).

Embora o survey não tenha captado a ocupação dos respondentes, já vimos anteriormente, para os dados populacionais, que a maior discrepância entre as mulheres brancas e negras não está no percentual de mulheres que trabalham, mas sim na categoria sócio-ocupacional em que está inserida. Desse modo, é possível afirmar que as mulheres negras acumulam desvantagens que tornam essa articulação mais tensa e cansativa, uma vez que seus trabalhos são mais mal remunerados, mais precários e menos protegidos. Soma-se a isso o fato de que são as mulheres negras que declararam em média mais horas dedicadas às tarefas domésticas.

A análise descritiva já nos oferece indicações importantes das diferenças entre as percepções de papéis de gênero e das práticas (realização das tarefas domésticas) e percepção do conflito na articulação família-trabalho. Mas, para analisar os efeitos das variáveis socioeconômicas e das características familiares sobre as percepções de papéis de gênero, práticas e conflito casa e trabalho, construímos um índice para cada dimensão, a partir das questões já exploradas na parte descritiva. Os índices variam de 0 a 1 , em que 1 é o polo positivo, a saber: (i) percepções e (ii) práticas igualitárias de papéis de gênero; e (iii) ausência de conflito casa-trabalho. ${ }^{3} 0$ Gráfico 1 apresenta as médias dos índices por sexo e cor.

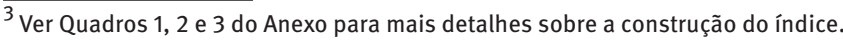


GRÁFICO 1

Média dos índices de percepções de papéis de gênero, práticas igualitárias e satisfação, por sexo e raça/cor

Brasil - 2016

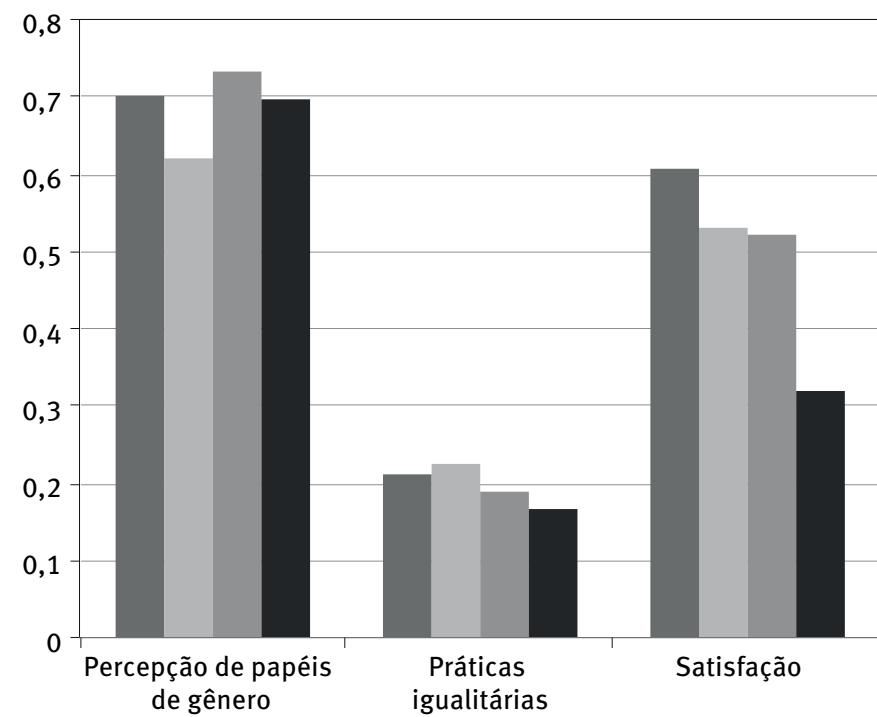

- Homem branco

Homem negro

Mulher branca

Mulher negra

Fonte: Pesquisa Gênero, Família e Trabalho, 2016. Elaboração das autoras.

0 índice de percepções de papéis de gênero mostra que, em média, as percepções mais igualitárias são das mulheres brancas, seguidas pelos homens brancos, mulheres negras e homens negros. Em relação às práticas, os valores em geral caem bastante e se distanciam de 1 , indicando que todos os grupos reportam pouco equilíbrio na distribuição das tarefas entre os casais. Os homens apresentam percepções ligeiramente mais otimistas em relação ao compartilhamento, quando comparados às mulheres, propensão constatada também no survey anterior (ARAÚJO; SCALON, 2005). E são os homens negros, seguidos pelos homens brancos, mulheres brancas e, por último, mulheres negras, aqueles que mais declararam dividir as tarefas domésticas. Como vimos anteriormente, os homens negros se destacam ao participarem no cuidado com familiares idosos e doentes, lavar e passar roupas e na limpeza da casa. Por fim, em relação ao conflito casa e trabalho, as mulheres negras, seguidas bem de longe pelas mulheres brancas, homens negros e homens brancos, são aquelas que mais declararam conflito na articulação família e trabalho. Vale salientar que o conflito nessa articulação significa, aqui, maior cansaço.

\section{Percepções de papéis de gênero e articulação família e trabalho: análises de regressão}

Utilizando os índices sobre percepções de papéis de gênero e conciliação trabalho-família, apresentados na seção anterior, como variáveis dependentes, aplicamos modelos de regressão linear múltipla para verificar como estes se relacionam com as características 
socioeconômicas e familiares dos grupos de interesse: homens brancos, homens negros, mulheres brancas e mulheres negras. Como variáveis independentes incluímos: idade (proxy para geração); escolaridade (proxy para aquisição de capital cultural e repertórios culturais); conjugalidade (viver com cônjuge); número de filhos (variáveis que expressam características dos arranjos e aumento de hora no trabalho doméstico); horas trabalhadas (sendo zero aqueles(as) sem trabalho declarado); se a mãe trabalhou fora quando o respondente tinha 15 anos (a mãe que trabalhou impacta em criar percepções mais igualitárias ou não); e frequência ao culto religioso (sendo zero aqueles(as) que não declararam ter religião ou que nunca frequentam cultos religiosos). Essa estratégia almeja lançar luz sobre as seguintes questões: como tais variáveis influenciam nas percepções de papéis de gênero? A transmissão intergeracional das desigualdades também se reverte na transmissão de valores desiguais? Os efeitos variam segundo os grupos de gênero e raça? Como variam? Os resultados estão apresentados na Tabela 5.

TABELA 5

Percepções de papéis de gênero: coeficientes padronizados

\begin{tabular}{lccccc}
\hline \multirow{2}{*}{ Variáveis } & \multicolumn{2}{c}{ Homens } & & \multicolumn{2}{c}{ Mulheres } \\
\cline { 2 - 3 } \cline { 5 - 6 } \cline { 5 - 6 } Idade & Brancos & Negros & & Brancas & Negras \\
Escolaridade & & $-0,183$ & & $-0,156$ & \\
Conjugalidade & 0,238 & 0,128 & & 0,178 & $-0,2$ \\
Número de filhos & $-0,198$ & & & $-0,188$ & $-0,255$ \\
Horas trabalhadas & & $-0,261$ & & $-0,126$ & \\
Mãe trabalhou fora & & & & 0,146 & 0,157 \\
Frequência religiosa & & $-0,128$ & & & $-0,111$ \\
R2 & 0,09 & 0,167 & & $-0,159$ & 0,16 \\
\hline
\end{tabular}

Fonte: Pesquisa Gênero, Família e Trabalho, 2016. Elaboração das autoras.

Nota: Modelos independentes de regressão linear múltipla, coeficientes significativos ( $p$-value >0,05)

Para as mulheres negras, ter uma mãe que trabalhou fora é a única variável que aumenta a adesão a papéis mais igualitários de gênero; o número de filhos, ter cônjuge e a alta frequência religiosa resultam numa menor simetria. Para as mulheres brancas, a única variável inserida na análise que não foi significante é ter tido uma mãe que trabalhou fora. A maior escolaridade e o maior número de horas trabalhadas ampliam a adesão a papéis igualitários, enquanto ser mais velha, ter cônjuge, maior número de filhos e frequentar culto religioso reduzem a percepção de papéis igualitários. Entre os homens negros, maior escolaridade e frequentar culto religioso resultam na maior adesão a papéis igualitários; e ser mais velho, ter maior número de filhos e ter uma mãe que trabalhou fora reduzem essa adesão. Para homens brancos, quanto maior a escolaridade, maior é a adesão a percepções mais igualitárias, mas ter um cônjuge diminui a percepção de simetria de gênero.

Os modelos apresentados evidenciam que as percepções dos homens brancos são impactadas por menos variáveis e em um sentido mais intuitivo: maior escolaridade, maior adesão a papéis igualitários e a presença de cônjuge expressam redução desta adesão. Além 
disso, o ajuste do modelo para o homem branco é o pior dos quatro modelos apresentados $\left(R^{2}=0,09\right)$. A socialização de gênero do homem branco parece, portanto, ser mais homogênea e, consequentemente, menos sensível a outras dimensões das experiências, como por exemplo o número de filhos, uma variável negativamente associada aos demais grupos.

Os homens negros, por sua vez, ao serem mais sensíveis a outras dimensões da experiência, colocam em evidência que os efeitos podem ir em outras direções, como por exemplo o efeito negativo de ter tido uma mãe que trabalha fora e o efeito positivo que a maior frequência religiosa tem. Em relação a ter mãe que trabalhou fora, vimos que entre os homens negros está o maior percentual de concordância com a afirmação de que o trabalho do homem é ganhar dinheiro e da mulher cuidar da casa. Soma-se a isso o fato que o trabalho das mulheres negras se dá em ocupações mais desvalorizadas, mal remuneradas e desprotegidas e sua inserção no mercado de trabalho pode estar mais vinculada à geração de renda para o cotidiano familiar do que para produção de sentido profissional e autonomia individual. Logo, o trabalho da mulher está vinculado à falta, seja de um homem provedor, seja de renda, e não necessariamente a um modelo igualitário de gênero (PICANÇO, 2004).

Em relação ao efeito positivo da frequência religiosa, é necessário “desvendar” como isso acontece. Inicialmente, vale nos remeter aos achados de Borges $(2017,2018)$ que, ao analisar a relação entre religião, percepções de papéis de gênero e prática de divisão do trabalho doméstico, já tinha identificado a tendência conservadora dos indivíduos que se declaram "sem religião, mas acreditam em Deus". Ele aponta como hipótese para isso a transição religiosa e a herança cultural. O Brasil é um país com forte peso da religiosidade na formação cultural e sistema de valores morais, podendo-se supor que parte considerável dos indivíduos sem religião já tenham passado por alguma religião em sua trajetória de vida ou tenham sido criados em famílias religiosas, mas não mantiveram o vínculo institucional com a religião. Nas duas hipóteses levantadas, não ter uma religião não significa necessariamente a ausência de uma socialização orientada por valores religiosos.

Analisamos a variável "frequência religiosa" e identificamos que, entre os que foram classificados como nenhuma frequência, $62 \%$ são indivíduos que declararam "sem religião, mas acreditam em Deus". Além disso, somamos mais três achados: entre aqueles que se declararam "sem religião, mas acreditam em Deus", observou-se o maior percentual de pessoas que concordam que "o trabalho do homem é ganhar dinheiro e da mulher cuidar da casa" e discordam que "um pai/mãe sozinho(a) pode cuidar do(a) filho(a)"; entre aqueles que se declararam "sem religião, mas acreditam em Deus", 59,5\% eram homens negros; e os homens negros que não declararam "sem religião, mas acreditam em Deus" registram o mais baixo índice de percepções de papéis de gênero, isto é, são em média os mais tradicionais em relação aos papéis de gênero, comparando-se tanto aos homens negros que declararam ter alguma religião e que as frequentam pelo menos algumas vezes, quanto aos demais grupos de gênero e raça/cor que não têm religião, mas acreditam em Deus.

Se, de um lado, encontramos os caminhos que nos ajudam a sustentar o achado do efeito positivo da frequência religiosa na adesão a papéis mais igualitários entre os 
homens negros, de outro, ainda há um espaço a ser explorado em pesquisas futuras de como esta adesão é produzida entre homens negros. Algumas hipóteses podem surgir a partir de estudos qualitativos sobre masculinidade entre homens negros e a socialização de gênero dos meninos negros.

As mulheres negras, ao não serem afetadas pela escolaridade, abrem espaço para que o campo da experiência esteja mais evidente tanto para produzir adesão a modelos mais tradicionais, quanto na recusa a este modelo. Daí que estar em arranjos tradicionais (cônjuge e filhos) e a experiência religiosa reduzem a adesão a valores mais igualitários. E a única dimensão que favorece é ter tido um modelo de mãe que trabalha. Com isso, ter tido uma mãe que trabalha tem efeito significativo, mas em sentidos opostos para homem negro e mulher negra.

Em relação à articulação casa e trabalho, inserimos na regressão idade, escolaridade, conjugalidade, número de filhos, número de moradores, horas dedicadas ao trabalho remunerado, ter empregada doméstica, frequência a culto religioso, índice de percepções e índice de práticas. A frequência ao culto religioso foi inserida para identificar se a adesão religiosa, mesmo sendo a qualquer matriz, produz uma acomodação e aceitação das tarefas cotidianas dos indivíduos sem, portanto, produzir conflitos e desconfortos. Os resultados são apresentados na Tabela 6.

TABELA 6

Conciliação trabalho-família: coeficientes padronizados

\begin{tabular}{|c|c|c|c|c|}
\hline \multirow[t]{2}{*}{ Variáveis } & \multicolumn{2}{|c|}{ Homens } & \multicolumn{2}{|c|}{ Mulheres } \\
\hline & Brancos & Negros & Brancas & Negras \\
\hline Idade & $-0,54$ & & & \\
\hline Escolaridade & & 0,449 & & 0,193 \\
\hline Conjugalidade & & 0,191 & 0,171 & $-0,214$ \\
\hline Número de filhos & 0,462 & & $-0,33$ & \\
\hline Número de moradores & & & $-0,236$ & $-0,148$ \\
\hline Horas trabalhadas & & & $-0,161$ & \\
\hline Tem empregada & 0,271 & & 0,337 & \\
\hline Frequência religiosa & & 0,276 & & 0,378 \\
\hline Índice de percepções & 0,23 & 0,261 & & \\
\hline Índice de práticas & & $-0,253$ & 0,196 & \\
\hline $\mathrm{R} 2$ & 0,38 & 0,30 & 0,37 & 0,32 \\
\hline
\end{tabular}

Fonte: Pesquisa Gênero, Família e Trabalho, 2016. Elaboração das autoras.

Nota: Modelos independentes de regressão linear múltipla, coeficientes significativos ( $p$-value >0,05).

Para as mulheres negras, quanto maiores a frequência religiosa e a escolaridade, menor é a declaração de cansaço, ao passo que ter cônjuge e ter maior número de moradores relacionam-se à maior declaração de cansaço. Para as brancas, ter empregada doméstica, ter práticas mais igualitárias e ter cônjuge reduzem o cansaço, enquanto maior número de filhos, maior número de moradores e maior número de horas trabalhadas aumentam o conflito casa-trabalho (cansaço). Para os homens negros, maior escolaridade, ter cônjuge, 
maior frequência a culto religioso e percepções mais igualitárias de gênero estão ligados a menor cansaço; e, quanto mais práticas compartilhadas, maior é cansaço. Entre os brancos, o número de filhos, ter empregada e percepções mais igualitárias geram menor cansaço; e quanto mais velho maior é o cansaço. Vale ressaltar que este é o modelo de melhor ajuste para os homens brancos $\left(R^{2}=0,38\right)$.

Observamos que os atenuantes do conflito casa-trabalho para as mulheres negras e brancas são distintos: se, para as negras, o maior efeito vem da religião, para as brancas é ter empregada doméstica. Nos achados anteriores vimos que a religião cumpre um papel não esperado (aumenta percepções igualitárias), pois não é entre aqueles que mais frequentam culto que encontramos os mais tradicionais. Mas em relação à declaração de cansaço, a religião impacta para mulheres e homens negros no sentido de protegê-los do cansaço. É possível, portanto, supor que a religião ofereça um espaço de acomodação, sentido de vida e estilo de vida que influenciam a percepção de cansaço. As brancas, por sua vez, buscam na delegação de suas tarefas o espaço para reduzir sua percepção de cansaço e o efeito que mais favorece o cansaço é o número de filhos, enquanto para as negras é ter cônjuge. Assim, ter um cônjuge causa impacto oposto entre brancas e negras.

\section{Conclusão}

Este artigo teve por objetivo analisar as percepções sobre papéis de gênero, práticas (divisão do trabalho doméstico entre casais) e conflito casa e trabalho remunerado, bem como observar a relação entre variáveis socioeconômicas e familiares com essas três dimensões, considerando uma perspectiva interseccional. Esta aposta analítica buscou evidenciar como as relações e as práticas sociais afetam os indivíduos de modo distinto em função das imbricações entre marcadores sociais de desigualdades, aqui considerados gênero e raça/cor.

Os resultados corroboram aspectos salientados pela literatura quanto à interação entre determinadas variáveis e valores mais ou menos igualitários nas relações de gênero (ARAÚJO et al., 2018; GUEDES, 2018; COVRE-SUSSAl et al., 2018). Mostram, ao mesmo tempo, que tais interações não se apresentam de maneira uniforme, seja entre mulheres, quando estas são agregadas segundo raça/cor, seja entre homens em situação idêntica.

No que se refere às percepções de papéis de gênero, as mulheres brancas, principalmente as mais escolarizadas, são as que apresentam percepções mais igualitárias. No entanto, isso diminui com maior número de filhos e a presença de cônjuge. Em contrapartida, os homens negros são os que demonstram percepções menos igualitárias e a adesão a esses papéis mais igualitários ainda é reduzido com a idade, maior número de filhos e ter convivido na adolescência com uma mãe que trabalhava. Mais idade, mais filhos e ter um cônjuge afetam negativamente as percepções das mulheres negras e brancas sobre os papéis de gênero. 
Embora as percepções sobre os papéis de gênero se mostrem bastante igualitárias em todos os grupos observados, as declarações sobre as relações de gênero, na prática, não confirmam essa simetria. Os homens negros, que apresentam a menor média no índice de percepções, são os mais igualitários no que se refere às práticas igualitárias nas relações conjugais, sugerindo que condições de necessidade influenciam as práticas. Essa adesão à igualdade aumenta com a escolaridade e com percepções mais igualitárias de papéis de gênero. Ao mesmo tempo, as mulheres negras reportam práticas mais desiguais, mas a simetria cresce com a escolaridade.

Em relação ao conflito casa e trabalho, os homens brancos e as mulheres negras apresentam realidades opostas. Enquanto os homens brancos são aqueles que declararam menor nível de conflito e maior conforto com essa relação, ou seja, estão mais bem acomodados nessa relação, as mulheres negras são as que reportam mais cansaço. A idade incide negativamente sobre a "satisfação" do homem branco, mas filhos, empregada doméstica e ter percepções mais igualitárias aumentam esse conforto. É interessante observar que os atenuantes do cansaço gerado pelo conflito casa-trabalho são diferentes para as mulheres brancas e negras. Enquanto para as negras o maior conforto vem da religião, para as brancas este vem das empregadas domésticas. De fato, parece que, enquanto a religião oferece um certo conforto subjetivo a homens e mulheres negros, para os homens e mulheres brancos este conforto vem mesmo das condições materiais, ou seja, poder delegar parte das tarefas às empregadas domésticas.

De uma forma geral, a escolaridade parece influenciar positivamente a articulação entre as três dimensões - papéis de gênero, práticas e conflito casa e trabalho, mensuradas aqui via incorporação dos índices às regressões de práticas e de conflito - para os quatro grupos de respondentes trabalhados - mulheres negras, mulheres brancas, homens negros e homens brancos. Salvo poucas exceções, quanto maior a escolaridade, maior é seu efeito positivo sobre as percepções aqui analisadas. De outra parte, em sentido oposto, a idade, o número de filhos e a conjugalidade são características com maior influência negativa, isto é, mais frequentemente associadas com papéis tradicionais, práticas de divisão de trabalho doméstico menos igualitárias e maior conflito casa e trabalho.

Sabe-se que um dos mais importantes ativos de capital social na vida contemporânea é a escolaridade. E isto adquire maior relevância em países muito desiguais, como o Brasil. Escolaridade afeta a formação e o grau de informação que os indivíduos possuem, assim como tem efeito sobre os tipos de ocupação e o grau de qualificação, sendo que estes aspectos, por sua vez, terão efeitos sobre a renda e o status dos indivíduos. Assim, não à toa, a escolaridade foi a variável significativa mais recorrente, inclusive para a análise do conflito casa e trabalho. Além disso, o peso geracional sobre valores e atitudes também se mostrou relevante e ocupou o segundo lugar em termos de frequência de significância. Contudo, como mencionado anteriormente, o peso de tais fatores não se apresentou uniforme entre os quatro grupos analisados, mas corroborou com o que a literatura tem 
indicado em inúmeros trabalhos: mulheres negras tendem a vivenciar situações de maior desigualdade e tais efeitos parecem se manifestar de modo direto e indireto.

A análise aqui desenvolvida mostrou que "gênero", "raça" e "classe" operam efetivamente como dimensões imbricadas e influenciam as percepções e práticas atitudinais dos indivíduos. 0 fato de o gênero ser um marcador de desigualdade recorrente no tempo e entre culturas ficou mais uma vez evidente neste artigo, como, por exemplo, na distribuição das tarefas domésticas e no efeito destas responsabilidades sobre as condições de (des)equilíbrio entre trabalho remunerado. Esse marcador, contudo, também varia em muitos aspectos, de tal modo que nem sempre homens negros e brancos ou mulheres negras e brancas se aproximam em suas percepções e vivências.

\section{Referências}

ABOIM, S.; WALL, K. Tipos de família em Portugal: interações, valores, contextos. Análise Social, v. 163, p. 411-446, 2002.

ALVES, J. E. D.; CARVALHO, A. A.; COVRE-SUSSAI, M. Divisão do trabalho doméstico e suas interfaces com gênero e raça no estado do Rio de Janeiro. In: ARAÚjO, C.; GAMA, A. (org.). Entre a casa e o trabalho: gênero e família no Rio de Janeiro. Rio de Janeiro: Nuderg/Uerj, 2017. p. 227-259.

ALVES, J. E. D.; CARVALHO, A. Valores igualitários por raça/cor no Brasil. In: ARAÚJO, C.; GAMA, A.; PICANÇO, F.; CANO, I. (org.). Gênero, família e trabalho no Brasil do século XXI: mudanças e permanências. Rio de Janeiro: Gramma Editora, 2018. p. 143-164.

ARAÚJO, C.; SCALON, M. C. Gênero, família e trabalho no Brasil. Rio de Janeiro: FGV, 2005.

ARAÚJO, C.; PICANÇO, F.; CANO, I.; VEIGA, A. Evolução das percepções de gênero, trabalho e família no Brasil: 2003-2016. In: ARAÚJO, C.; GAMA, A.; PICANÇO, F.; CANO, I. (org.). Gênero, família e trabalho no Brasil do século XXI: mudanças e permanências. Rio de Janeiro: Gramma Editora, 2018. p. 15-45.

BADINTER, E. O conflito: a mulher e a mãe. Rio de Janeiro: Record, 2011.

BLEE, K. M.; TICKAMYER, A. R. Racial differences in men's attitudes about women's gender roles. Journal of Marriage and the Family, v. 57, n. 1, p. 21-30, 1995.

BORGES, D. Em nome do pai, da mãe e do Espírito Santo: arranjos familiares e religião no Brasil contemporâneo. In: ARAÚJO, C.; GAMA, A.; PICANÇO, F.; CANO, I. (org.). Gênero, família e trabalho no Brasil do século XXI: mudanças e permanências. Rio de Janeiro: Gramma Editora, 2018. p. 165-246.

BORGES, D. Gênero e religião: uma análise das diferenças entre os valores e atitudes sobre família no Rio de Janeiro. In: ARAÚJO, C.; GAMA, A. (org.). Entre a casa e o trabalho: gênero e família no Rio de Janeiro. Rio de Janeiro: Nuderg/Uerj, 2017. p. 259-288.

BRUSCHINI, C. Trabalho doméstico: inatividade econômica ou trabalho não-remunerado? Revista Brasileira de Estudos de População, v. 23, n. 2, p. 331-353, 2006.

BRUSCHINI M. C.; RICOLDI, A. M. Revendo estereótipos: o papel dos homens no trabalho doméstico. Revista Estudos Feministas, v. 20, n. 1, p. 259-87, 2012.

BUCHANAN, T.; SELMON, N. Race and gender differences in self-efficacy: assessing the role of gender role attitudes and family background. Sex Roles: A Journal of Research, v. 58, n. 11-12, 
p. 822-836, 2008.

BURGESS, N. Gender roles revisited: the development of the "woman's place among African American women in the United States”. Journal of Black Studies, v. 24, p. 391-401, 1994.

CHO, S.; CRENSHAW, K. W.; MCCALL, L. Toward a field of intersectionalities studies: theory, application, praxis. Journal of Women in Culture and Society, v. 38, n. 4, p. 785-810, 2013.

CRENSHAW, K. Mapping the margins: intersectionality, identity politics and violence against women of color. In: FINEMAN, M.; MYKITIUK, R. (org.). The public nature of private violence. New York: Routledge, 1994.

COLLINS, P. H. Intersectionality's definitional dilemmas. Annual Review of Sociology, n. 41, p. 1-20, 2015.

COLLINS, P. H. Black feminist thought: knowledge, consciousness, and the politics of empowerment. 2. ed. London: HarperCollins, 1999.

COVRE-SUSSAI, M. Socioeconomic and cultural features of consensual unions in Brazil. Revista Brasileira de Estudos de Populacão, v. 33, n. 1, p. 53-74, 2016.

COVRE-SUSSAI, M.; SOARES, J.; RODRIGUES, T. Relações de gênero nas famílias brasileiras: conjugalidades, valores e percepções. In: ARAÚJO, C.; GAMA, A.; PICANÇO, F.; CANO, I. (org.). Gênero, família e trabalho no Brasil do século XXI: mudanças e permanências. Rio de Janeiro: Gramma Editora, 2018. p. 129-142.

CROMPTON, R. Employment and the family, the reconfiguration of work and family life in the contemporary societies. Cambridge: Cambridge University Press, 2006.

CROMPTON, R.; LYONETTE, C. Work-life "balance" in Europe. Acta Sociologica, v. 49, n. 4, p. 379-393, 2006.

CURRY, T. J. The man-not: race, class, gender, and the dilemmas of black manhood. Philadelphia, Pennsylvania: Temple University Press, 2017.

ESTEVE, A.; LESTHAEGHE, R. J.; LOPEZ-COLAS, J.; LOPEZ-GAY, A.; COVRE-SUSSAI, M. Cohabitation in Brazil, 1970-2010. Historical legacy and recent evolution. In: ESTEVE, A.; LESTHAEGHE, R. Cohabitation and marriage in the Americas: geo-historical legacies and new trends. Barcelona: Springer Publishing Company, 2016. p. 217-246.

FERREE, M. M. A woman for president? Changing responses: 1958-1972. The Public Opinion Quarterly, v. 38, n. 3, p. 390-3999, 1974.

GAMA, A.; SORJ, B.; ROMERO, K.; VEIGA, A. Tensões entre trabalho e família - recomposições na divisão sexual do trabalho. In: ARAÚJO, C.; GAMA, A.; PICANÇO, F.; CANO, I. (org.). Gênero, família e trabalho no Brasil do século XXI - mudanças e permanências. Rio de Janeiro: Gramma, 2018. p. 83-113.

GARNEAU, S. Intersectionality beyond feminism? Some methodological and epistemological considerations for research. International Review of Sociology/Revue Internationale de Sociologie, v. 28, n. 2, p. 321-335, 2018.

GUEDES, M. Escolaridade e gênero: percepções mais igualitárias? In: ARAÚJO, C.; GAMA, A.; PICANÇO, F.; CANO, I. (org.). Gênero, família e trabalho no Brasil do século XXI - mudanças e permanências. Rio de Janeiro: Gramma, 2018. p. 115-128.

GUIMARÃES, A. S. A. Formações nacionais de classe e raça. Tempo Social, v. 28, n. 2, p. 161-182, 2016. 
GUIMARÃES, N. A.; BRITO, M. Mercantilização no feminino - a visibilidade do trabalho das mulheres no Brasil. In: ABREU, A.; HIRATA, H.; LOMBARDI, M. (org.). Gênero e trabalho no Brasil e na França: perspectivas intersecionais. São Paulo: Boitempo, 2016.

HANCOCK, A. M. Empirical intersectionality: a tale of two approaches. U.C. Irvine Law Review, v. 3, n. 2, p. 259-296, 2013. Disponível em: https://scholarship.law.uci.edu/ucilr/vol3/iss2/6.

HASENBALG, C. Discriminação e desigualdades raciais no Brasil. Rio de Janeiro: Graal, 1979.

HERINGER, R.; MIRANDA, D. As cores da desigualdade de gênero no Brasil. In: ARAÚJO, C.; SCALON, C. M. Gênero, família e trabalho no Brasil. Rio de Janeiro: FGV, 2005.

HIRATA, H. Mundialização, divisão sexual do trabalho e movimentos feministas transnacionais. Cadernos de Crítica Feminista, Ano 3, n. 2, 2009.

HIRATA, H. Gênero, classe e raça: interseccionalidade e consubstancialidade das relações sociais. Tempo Social, v. 26, n. 1, p. 62-73, 2014.

HIRATA, H.; KERGOAT, D. Novas configurações da divisão sexual do trabalho. Cadernos de Pesquisa, v. 37, n. 132, p. 595-609, 2007.

IPEA - Instituto de Pesquisa Econômica Aplicada. Retrato das desigualdades de gênero e raça 1995-2015. Brasília: Ipea, 2017. Disponível em: http://www.ipea.gov.br/portal/images/stories/ PDFs/170306_retrato_das_desigualdades_de_genero_raca.pdf. Acesso em: 20 jul. 2018.

ITABORAÍ, N. R. Mudanças nas famílias brasileiras (1976-2012): uma perspectiva de classe e gênero. Rio de Janeiro: Garamond, 2017.

JOAS, H. The genesis of values. University of Chicago Press, 2000.

KERGOAT, D. Dinâmica e consubstancialidade das relações sociais. Novos Estudos, v. 86, p. 93-103, mar. 2010.

LICHTER, D. T.; MCLAUGHLIN, D. K.; KEPHART, G.; LANDRY, D. J. Race and the retreat from marriage: a shortage of marriageable men? American Sociological Review, v. 57, n. 6, p. 781-799, 1992.

LINDSEY, L. Gender roles. A sociological perspective. New York: Routledge, 2016.

LOMAZZI, V.; SEDDIG, D. Gender role attitudes in the international social survey programme: Cross-National Comparability and Relationships to Cultural Values. Cross-Cultural Research, v. 54, n. 4, p. 398-431, 2020.

MCCALL, L. The complexity of intersectionality. Signs. Journal of the Woman in Culture and Society, v. 30, n. 3, p. 1771-1800, 2005.

MALADOZZO, R.; MARTINS, S. R.; SHIRATORI, L. Participação no mercado de trabalho e no trabalho doméstico: homens e mulheres têm condições iguais? Estudos Feministas, v. 18, n. 2, p. 547-566, 2010.

MILES, A. The (re)genesis of values: examining the importance of values for action. American Sociological Review, v. 80, n. 4, p. 680-704, 2015.

O'CONNOR, C.; BRIGHT, L. K.; BRUNER, J. P. The emergence of intersectional disadvantage. Social Epistemology, v. 33, n. 1, p. 23-41, 2019. DOI: 10.1080/02691728.2018.1555870.

OLUWAYOMI, A. The man-not and the inapplicability of intersectionality to the dilemmas of black manhood. The Journal of Men's Studies, v. 28, n. 2, p. 183-205, 2020.

PASSOS, L.; WAJNMAN, S. Diferencial salarial entre as mulheres: a penalidade da cor. In: 43은 ENCONTRO ANUAL DA ANPOCS. Anais [...]. Caxambu: Anpocs, 2019. 
PICANÇO, F. Economic modernization and socio-occupational mobility in Brazil. Communication at the International Sociological Association, RC28, 2004.

PINHEIRO, L. S. Determinantes da alocação de tempo em trabalho reprodutivo: uma revisão sobre os achados em pesquisas nacionais e internacionais. In: FONTOURA, N.; ARAÚJO, C. (ed.). Uso do tempo e gênero. Rio de Janeiro: Uerj, 2016. p. 61-99.

RALEY, R. K. A shortage of marriageable men? A note on the role of cohabitation in black-white differences in marriage rates. American Sociological Review, v. 61, p. 973-983, 1996.

SAMARA, E. D. M.; COSTA, D. I. P. Family, patriarchalism, and social change in Brazil. Latin American Research Review, v. 32, n. 1, p. 212-225, 1997.

SARTOR, A. Paternidades: pais em transformação. Tese (Doutorado em Ciências Sociais) Universidade do Estado do Rio de Janeiro (Uerj), Rio de Janeiro, 2017.

SCHWARTZ, S. H. An overview of the Schwartz theory of basic values. Online Readings in Psychology and Culture, v. 2, n. 1, p. 2307-0919, 2012.

SINGLY, F. Sociologia da família contemporânea. Rio de Janeiro: Editora FGV, 2007.

SMOCK, P. J. Cohabitation in the United States: an appraisal of research themes, findings, and implications. Annual Review of Sociology, v. 26, p. 1-20, 2000.

THEODORO, M. A formação do mercado de trabalho e a questão racial no Brasil. In: THEODORO, M.; JACCOUD, L.; OSÓRIO, R. G.; SOARES, S. As políticas públicas e a desigualdade Racial no Brasil 120 anos após a abolição. Brasília: Ipea, 2008. p. 15-43.

THERBORN, G. Sexo e poder: a família no mundo 1900-2000. Tradução de Elisabete Doria Bilac. São Paulo: Editora Contexto, 2006.

TORRES, A. Vida conjugal e trabalho. Oeiras: Celta Editora, 2004.

VESPA, J. Gender ideology construction: a life course and intersectional approach. Gender \& Society, v. 23, n. 3, p. 363-387, 2009.

\section{Sobre as autoras}

Felícia Picanço é doutora em Sociologia. Professora do Departamento de Sociologia e do Programa de Pós-Graduação em Sociologia e Antropologia da Universidade Federal do Rio de Janeiro (UFRJ).

Clara Maria de Oliveira Araújo é doutora em Sociologia. Professora do Departamento de Sociologia e do Programa de Pós-Graduação em Ciências Sociais da Universidade Estadual do Rio de Janeiro (UERJ).

Maira Covre-Sussai é doutora em Ciências Sociais. Professora do Departamento de Sociologia e do Programa de Pós-Graduação em Ciências Sociais da Universidade Estadual do Rio de Janeiro (UERJ). 


\title{
Endereço para correspondência
}

\author{
Felícia Picanço \\ Largo de São Francisco de Paula, 1, sala 420, Centro \\ 20051-070 - Rio de Janeiro-RJ, Brasil \\ Clara Maria de Oliveira Araújo \\ Universidade do Estado do Rio de Janeiro \\ Rua São Francisco Xavier, 524, sala 9034, bloco A, Maracanã \\ 20550-900 - Rio de Janeiro-RJ, Brasil \\ Maira Covre-Sussai \\ Universidade do Estado do Rio de Janeiro \\ Rua São Francisco Xavier, 524, sala 9034, bloco A, Maracanã \\ 20550-900 - Rio de Janeiro-RJ, Brasil
}

\begin{abstract}
Gender roles and division of domestic work by gender and race in Brazil: other views on inequalities
\end{abstract}

Adherence to the traditional family model has never been uniform. Studies of black families in the US show that black women are less likely than white women to officiate marriage, less dependent on their spouses, and regarding their attitude, African American men and women tend to be more tolerant of mothers who work and are more egalitarian in relation to gender roles. Differences are attributed to the socioeconomic constraints experienced historically and to the solutions built to deal with them. But what about Brazil? The article analyzes data from the Gender and Family survey regarding perceptions in relation to i) gender roles, ii) practices of division of domestic work among members of the couple and iii) conflict in the articulation between paid and unpaid work according to gender and race. Results show that white women have more equality and this adherence increases with schooling and decreases with a greater number of children and the presence of a spouse. Moreover, black men are the least egalitarian and this asymmetry is reduced by age and a greater number of children. Regarding division of labor, black men are the most egalitarian and adherence to equality increases with schooling and with more egalitarian perceptions of gender roles; whereas black women report less symmetrical relationships, but symmetry grows with schooling. In relation to the home-work conflict, black women declare more tiredness, but this decreases with schooling and the presence of a spouse.

Keywords: Gender. Family. Gender roles. Work-family balance.

\section{Resumen}

Roles de género y división de tareas domésticas según género y raza en Brasil: otros puntos de vista sobre las desigualdades

La adhesión al modelo familiar tradicional nunca ha sido uniforme. Los estudios sobre familias negras en los Estados Unidos muestran que las mujeres negras son menos propensas que las 
mujeres blancas a casarse, son menos dependientes de sus cónyuges y, desde el punto de vista de la actitud, los hombres y las mujeres afroamericanas tienden a ser más tolerantes con las madres. quienes trabajan y son más igualitarios en relación con los roles de género. Las diferencias se atribuyen a las limitaciones socioeconómicas experimentadas históricamente y a las soluciones creadas para enfrentarlas. ¿Y en Brasil? El artículo analiza los datos de la Encuesta de Género y Familia a partir de las percepciones en relación con 1) los roles de género, 2) las prácticas de división del trabajo doméstico entre los miembros de la pareja y 3) el conflicto en la articulación entre el trabajo remunerado y no remunerado según el género y raza. Los resultados muestran que las mujeres blancas son las más iguales y esta adherencia crece con la escolaridad y se reduce con un mayor número de hijos y la presencia de un cónyuge, y que los hombres negros son los menos igualitarios y que esta asimetría se reduce por la edad y un mayor número de niños. En la división del trabajo, los hombres negros son los más igualitarios y la adhesión a la igualdad aumenta con la escolarización y con percepciones más igualitarias de los roles de género, y las mujeres negras reportan relaciones menos simétricas, y esa simetría crece con la escolarización. En relación con el conflicto del trabajo en el domicilio, las mujeres negras declaran más cansancio, pero esto se reduce con la escolarización y la presencia de un cónyuge.

Palabras clave: Género. Familia. Roles de género. Articulación casa y trabajo.

Recebido para publicação em 15/10/2020 Aceito para publicação em 12/07/2021 


\section{ANEXO}

TABELA 1

Distribuição das pessoas acima de 18 anos, por sexo e raça/cor, segundo quintil de renda Brasil - 2014

\begin{tabular}{|c|c|c|c|c|c|}
\hline \multirow{3}{*}{ Quintis } & & & & & \multirow[t]{2}{*}{ Em porcentagem } \\
\hline & \multicolumn{2}{|c|}{ Homens } & \multicolumn{2}{|c|}{ Mulheres } & \\
\hline & Brancos & Negros & Brancas & Negras & Total \\
\hline Sem renda & 5,6 & 4,3 & 5,5 & 4,5 & 5,0 \\
\hline $1 \underline{0}$ & 7,4 & 17,4 & 7,9 & 20,0 & 13,5 \\
\hline $2^{\circ}$ & 12,1 & 19,2 & 12,4 & 20,5 & 16,3 \\
\hline 30 & 17,3 & 22,0 & 18,1 & 21,9 & 19,9 \\
\hline $4 \stackrel{0}{2}$ & 24,3 & 21,5 & 23,8 & 19,3 & 22,0 \\
\hline $5^{0}$ & 33,4 & 15,6 & 32,2 & 13,8 & 23,2 \\
\hline Total & 100,0 & 100,0 & 100,0 & 100,0 & 100,0 \\
\hline
\end{tabular}

Fonte: PNAD-IBGE, 2014. Elaboração das autoras.

TABELA 2

Distribuição das pessoas acima de 18 anos, por sexo e raça/cor, segundo categorias sócio-ocupacionais Brasil - 2014

\begin{tabular}{|c|c|c|c|c|c|}
\hline \multirow{3}{*}{ Categorias sócio-ocupacionais } & & & \multicolumn{3}{|c|}{ Em porcentagem } \\
\hline & \multicolumn{2}{|c|}{ Homens } & \multicolumn{2}{|c|}{ Mulheres } & \multirow{2}{*}{ Total } \\
\hline & Brancos & Negros & Brancas & Negras & \\
\hline Profissionais liberais & 3,9 & 0,9 & 3,6 & 0,8 & 2,3 \\
\hline Dirigentes & 4,5 & 2,0 & 4,2 & 1,8 & 3,0 \\
\hline Proprietários empregadores & 4,4 & 1,6 & 2,6 & 0,9 & 2,4 \\
\hline Profissionais de nível superior & 4,8 & 2,3 & 12,4 & 7,5 & 6,3 \\
\hline Técnicos e artistas & 11,8 & 8,6 & 10,1 & 7,9 & 9,6 \\
\hline Pequenos proprietários & 0,0 & 0,0 & 0,0 & 0,0 & 0,0 \\
\hline Ocupações não manuais de rotina & 12,0 & 9,2 & 23,6 & 18,9 & 15,1 \\
\hline Ocupações na indústria moderna & 9,0 & 8,8 & 1,0 & 0,8 & 5,4 \\
\hline Ocupações na indústria tradicional & 13,3 & 20,6 & 5,9 & 5,9 & 12,3 \\
\hline Comércio ambulante & 3,3 & 3,5 & 4,0 & 5,9 & 4,1 \\
\hline Ocupações nos serviços gerais & 15,2 & 18,3 & 5,1 & 7,1 & 12,2 \\
\hline Ocupações nos serviços pessoais & 2,7 & 2,8 & 8,9 & 11,2 & 5,9 \\
\hline Ocupações no serviço doméstico & 0,6 & 0,9 & 10,1 & 17,6 & 6,5 \\
\hline Proprietários rurais & 0,6 & 0,3 & 0,1 & 0,0 & 0,3 \\
\hline Ocupações rurais & 13,0 & 19,2 & 7,8 & 12,8 & 13,8 \\
\hline Outras & 0,9 & 1,1 & 0,7 & 0,9 & 0,9 \\
\hline Total & 100,0 & 100,0 & 100,0 & 100,0 & 100,0 \\
\hline
\end{tabular}

Fonte: PNAD-IBGE, 2014. Elaboração das autoras. 


\section{QUADRO 1}

Criação do índice "percepções de papéis de gênero"

Cada resposta considerada como adesão a percepções igualitárias foi pontuada com o valor 1. 0 índice é a soma das respostas 1 e depois padronizado para variar de 0 a 1 .

\begin{tabular}{|lll|}
\hline Mulher que trabalha fora pode ter relação tão carinhosa quanto a que não trabalha & Concorda & 1 \\
\hline Vida familiar fica prejudicada se a mulher trabalha fora & Discorda & 1 \\
\hline Trabalho do homem é ganhar dinheiro e da mulher cuidar da casa & Discorda & 1 \\
\hline Homens deveriam dividir igualmente as tarefas domésticas & Concorda & 1 \\
\hline Pai ou mãe sozinho(a) pode criar o(a) filho(a) tão bem quanto um casal & Concorda & 1 \\
\hline
\end{tabular}

QUADRO 2

Criação do índice "práticas da divisão do trabalho doméstico entre os membros do casal"

Cada resposta considerada como práticas igualitárias foi pontuada com o valor 1. 0 índice é a soma das respostas 1 e depois padronizado para variar de 0 a 1.

\begin{tabular}{|lll|}
\hline Lava e passa & Divide igualmente & 1 \\
\hline Faz pequenos consertos & Divide igualmente & 1 \\
\hline Cuida dos familiares doentes idosos & Divide igualmente & 1 \\
\hline Compra comida & Divide igualmente & 1 \\
\hline Limpa a casa & Divide igualmente & 1 \\
\hline Cozinha & Divide igualmente & 1 \\
\hline Lava a louça & Divide igualmente & 1 \\
\hline
\end{tabular}

\section{QUADRO 3}

\section{Criação do índice "conflito casa-trabalho"}

Cada resposta considerada como expressão de ausência de conflito casa-trabalho foi pontuada com o valor 1.

$\mathrm{O}$ índice é a soma das respostas 1 e depois padronizado para variar de 0 a 1.

\begin{tabular}{|lll|}
\hline Chega do trabalho cansado demais & Nunca & 1 \\
\hline Difícil cumprir responsabilidades familiares por causa do trabalho & Nunca & 1 \\
\hline Tem chegado cansado no trabalho por causa de tarefas domésticas & Nunca & 1 \\
\hline
\end{tabular}

